\title{
A CULTURA E A SOCIALIZAÇÃO NA FORMAÇÃO DA CRIANÇA
}

\section{ARTIGO DE REVISÃO}

NASCIMENTO, Márcio Moreira Do ${ }^{1}$

NASCIMENTO, Márcio Moreira Do. A cultura e a socialização na formação da criança. Revista Científica Multidisciplinar Núcleo do Conhecimento. Ano 05, Ed. 08, Vol. 02, pp. 88-106. Agosto de 2020. ISSN: 2448-0959, Link de acesso: https://www.nucleodoconhecimento.com.br/pedagogia/cultura-e-a$\underline{\text { socializacao }}$

\section{RESUMO}

O presente trabalho consiste em um estudo sobre a infância, cultura e a socialização na formação da criança. Trata-se de uma análise acerca da comunicação mercadológica abusiva dirigida às crianças e as implicações para esses sujeitos que sofrem toda a forma de exploração possível. Propõe-se uma bibliográfica, e, assim, utilizou-se de livros, artigos e sites. Percebe-se que a socialização da criança é mediada primeiro pela família e depois pelas diferentes instituições sociais, bem como pela ideologia presente em cada uma delas. Nesse sentido, a cultura e socialização na formação da criança perpassa a influência que o indivíduo sofre do mundo, dos processos de socialização e dos determinantes históricos, sociais e simbólicos que o envolvem. O trabalho apresenta-se com os seguintes tópicos: a infância, a socialização, um enfoque: a prática da socialização na vida diária da criança, um agente fundamental a família, uma ação fundamental - a fala, contextos socioculturais, desvios da socialização e ações vitimadoras da criança, meios de comunicação, novos agentes de socialização, usos e abusos dos meios de comunicação e, por fim, as considerações finais. A infância é mais um produto mercadológico, e, assim, sofre

\footnotetext{
${ }^{1}$ Mestrando em Geografia (UFMS - Aquidauana), Especialização em Gestão Escolar; Graduação em Pedagogia.
} 
toda a forma de exploração possível e a família é a responsável pela educação digital e pela preservação da infância.

Palavras-chave: Cultura, socialização, formação da criança.

\section{INTRODUÇÃO}

A sociedade passa por transformações culturais e sociais de grande importância, como o acelerado avanço tecnológico e científico. Nesse contexto, em razão da expansão da tecnologia e da crescente globalização da economia e cultura, as novas gerações sofrem com a comunicação mercadológica direcionada à criança de forma abusiva. O presente trabalho consiste em um breve estudo sobre a infância, cultura e a socialização, apontando a necessidade de acompanhamento familiar no dia-a-dia da criança para evitar o desenvolvimento prematuro e possíveis problemas causados pela visão mercadológica e capitalista abusiva direcionada às crianças. Trata-se de uma análise acerca da comunicação mercadológica dirigida às crianças e as implicações para esses sujeitos que sofrem toda a forma de exploração possível. A pesquisa é bibliográfica e utilizou-se de livros, artigos e sites.

Percebe-se que a socialização da criança é mediada primeiro pela família e depois pelas diferentes instituições sociais, moldadas pela ideologia presente nestas empresas. Nesse sentido, a compreensão da cultura e socialização na formação da criança perpassa a influência que o indivíduo sofre do mundo, os processos de socialização e os determinantes históricos, sociais e simbólicos que o envolvem. $\mathrm{O}$ trabalho discute acerca da infância, da socialização e da prática da socialização na vida diária da criança - um agente fundamental a família. Discute-se, ainda, sobre uma ação fundamental - a fala; sobre os contextos socioculturais, desvios da socialização e ações vitimadoras da criança e sobre os meios de comunicação e novos agentes de socialização, assim como sobre os usos e abusos midiáticos. A infância é mais um produto mercadológico, e, assim, sofre toda a forma de exploração possível, sendo a família a responsável pela educação digital e preservação da infância. 
As ações socializadoras dos meios de comunicação estão profundamente vinculadas à cultura de consumo. É neste cenário que vamos encontrar os focos mais poderosos de novos estímulos aos usos e abusos da criança, convertendo-a em mediação de violência contra si mesma. Este artigo delimitou-se em colher informações sobre a infância, cultura e a socialização para refletir sobre a comunicação mercadológica direcionada à criança de forma abusiva, tendo, como referência, pesquisas em artigos, revistas e livros sobre o tema. Diante do que foi apresentado, percebeu-se o problema da comunicação mercadológica direcionada à criança de forma abusiva. Esta situação pode ser resolvida com a discussão entre entidades que trabalham com este público e as famílias das crianças, abordando os conceitos de infância, cultura e a socialização da criança, apontando a necessidade do acompanhamento familiar no dia-a-dia da criança.

Deve-se, portanto, obedecer as etapas de desenvolvimento para evitar possíveis os problemas causados pela visão mercadológica e capitalista da infância. O presente trabalho tem como objetivo discutir os impactos causados pela comunicação mercadológica abusiva ao público infantil, abordando, para isso, a importância da família em conhecer os conceitos de infância, cultura e a socialização para evitar problemas no desenvolvimento da criança, que, por sua vez, são suscitados pela visão mercadológica e capitalista acerca da infância.

\section{MATERIAIS E MÉTODOS}

Esse estudo tem por finalidade realizar uma pesquisa aplicada, uma vez que utilizará conhecimento da pesquisa fundamental para resolver problemas. Observou-se que a pesquisa aqui proposta é classificada como uma pesquisa exploratória. Detectou-se, também, a necessidade da pesquisa bibliográfica, pois fez-se uso de materiais já elaborados: livros, artigos científicos, revistas e documentos eletrônicos, necessários à busca pelo conhecimento sobre a infância, cultura e a socialização da criança para evitar o abuso, correlacionando tal conhecimento com abordagens já trabalhadas por outros autores. A pesquisa é bibliográfica e explicativa, e, dessa forma, proporciona uma maior familiaridade com o problema, tornando-o explícito ou construindo hipóteses sobre ele. 
Sobre as técnicas empregadas, deve-se mencionar o levantamento bibliográfico, pois, a partir dele, obteve-se as bibliografias, o que torna a pesquisa, também, bibliográfica, uma vez que implica que os dados e informações necessárias para realização da pesquisa sejam obtidos a partir do apuramento de autores especializados por meio de livros, artigos científicos e revistas especializadas, dentre outras fontes. O problema foi direcionando a pesquisa para as áreas de publicidade e educação à comunicação mercadológica direcionada à criança, que é abusiva, sendo este conhecimento sobre a infância, cultura e a socialização da criança uma análise necessária para evitar o abuso. A pesquisa parte do princípio de que a infância precisa ser compreendida e respeitada.

\section{A INFÂNCIA}

Sob a dimensão cultural, a infância remete à socialização e à aquisição da cultura e um dos agentes importantes neste processo é a aquisição da fala. No livro "O Emílio", Rousseau (1995), na contramão da tradição cultural dominante, apresenta uma visão da criança como adulto inacabado, e, assim, postulava que a infância possui modos de ver, de pensar, de sentir que lhe são próprios. Esse ponto de vista, todavia, não chegou a afetar a prática social.

Foram propostos dois modelos diferentes do processo de socialização. O primeiro é um modelo determinista, no qual a criança desempenha basicamente um papel passivo. Nessa vertente, a criança é simultaneamente uma "iniciante" com potencial para contribuir para a manutenção da sociedade e uma "ameaça indomada" que deve ser controlada por meio de treinamento cuidadoso. No segundo, um modelo construtivista, a criança é vista como agente ativo e um ávido aprendiz. Sob essa perspectiva, a criança constrói ativamente seu mundo social é seu lugar nele (CORSARO, 2011, p. 19)

No entanto, a criança continuou sendo pensada como adulto miniaturizado. Ao analisarmos do ponto de vista da humanização, é possível inferir que a criança é um humano a ser introduzido na ordem da cultura, a partir da socialização. O processo de socialização é um objeto de pensamento multidisciplinar, pois envolve diferentes dimensões do fenômeno histórico, econômico, psicológico, pedagógico, social e antropológico. Nosso foco de interesse é a dimensão antropológica, mas essa 
dimensão não se "descola" das demais, e, por isso, em muitas vezes, incursionaremos por áreas próximas à essas disciplinas. Quando o fizermos, todavia, é indispensável ter claro que o lugar de onde falamos inscreve-se no campo da Antropologia. A inserção da criança no mundo da cultura começa a se fazer muito antes do nascimento, uma vez que a posição social de seus pais define seu lugar na sociedade, e, desse modo, supomos que a inserção formal de uma dada criança no mundo da cultura se inicia com seu nascimento.

A socialização primária decorre durante a infância e constitui o período mais intenso de aprendizagem cultural. É a altura em que a criança aprende a falar e aprende os mais básicos padrões comportamentais que são os alicerces de aprendizagens posteriores. Nesta fase, a família é o principal agente de socialização. A socialização secundária decorre desde um momento mais tardio na infância até à idade adulta. Nesta fase, outros agentes de socialização assumem de alguma da responsabilidade que pertencia à família (GIDDENS; FIGUEIREDO; SOBRAL, 2008, p. 28-29).

A família é o principal agente de socialização, mas não deixaremos de referir outros agentes. Procuraremos iluminar os desvios da socialização e desvelaremos usos e abusos da criança em nossa sociedade, procurando dar visibilidade à violência que as atinge.

\section{A SOCIALIZAÇÃO}

Segundo Elkin (1968), a socialização inclui tanto a aprendizagem quanto apreensão de padrões, valores e sentimentos próprios da sociedade. A criança não apenas sabe intelectualmente o que é esperado dela e se comporta de acordo.

Socializar é criar condições de cooperação no estabelecimento das "regras do jogo" a cooperação produz, mentalmente, as operações superiores, da inteligência e, socialmente, a negociação das relações mútuas (segundo uma lei imanente - equilibração - de "máximo de lucros e mínimo de perdas" (LIMA, 1980, p. 84)

Logo, temos um problema pedagógico que é superar a coação dos adultos sobre o comportamento da criança. As principais ações de socialização se orientam em direção à diferentes focos e significações do ser da criança, compreendendo-se, 
nesse processo, a sua entidade biológica, sua entidade psíquica, sua entidade social e cultural, e, ainda, os diversos mundos que habita, o mundo das coisas, das pessoas, das ideias. O indivíduo no processo de socialização entra em comunicação com o social a partir de símbolos. Desse modo:

A medida que vão ficando mais velhas, as crianças vão se tornando mais hábeis na utilização de símbolos para se comunicar com os outros. Os símbolos são os gestos os objetos e as palavras que formam a base da comunicação humana interagindo com parentes e amigos, bem como assistindo desenhos animados na televisão e vendo livros com fotos, as crianças na fase preparatória começam a entender a questão dos símbolos. Elas continuarão utilizando essa forma de comunicação durante toda a vida (SCHAEFER, 2006, p. 84).

O símbolo, nesse contexto, é algo a que se atribui valor ou significado. Tal atribuição, por sua vez, é designada por todos aqueles que o utilizam na sua interação e interrelação. O símbolo tem imensa possibilidade de materialidade: pode ser uma forma, uma cor, um cheiro, um movimento, um som, um sabor, um gesto, uma palavra. É mediante o símbolo que atribuímos sentido; é com ele, portanto, que significamos em nossa existência. Por exemplo, quando pronunciamos uma palavra, os agrupamentos de sons, ao serem pronunciados, garantem materialidade sonora à símbolos verbais que podem representar sentimentos de quem fala. O símbolo verbal é dominante na socialização, e, assim, a palavra tem um potencial enorme na comunicação humana.

Em qualquer sociedade, nascemos imersos no simbólico e vamos aprendendo a lidar com eles, a operar com eles, a brincar com eles, a pensar e sentir com eles, a nos lambuzar com eles, até que deles estejamos tão impregnados que se tornam parte de nossa natureza, e, assim, tais símbolos nos distingue enquanto humanidade. É bom lembrar que não há sociedade humana sem cultura e não há cultura sem uma sociedade. Outro aspecto da socialização é o de ser um processo fundamental tanto para a interação indivíduo-cultura, indivíduo-sociedade como para garantir a continuidade da sociedade e da cultura. É por meio do processo de aprendizagem, de socialização, que os indivíduos se tornam herdeiros de uma tradição cultural e a transmitem, tornando-se, pela cultura, membros de uma sociedade. 


\section{UM ENFOQUE: A PRÁTICA DA SOCIALIZAÇÃO NA VIDA DIÁRIA DA CRIANÇA}

Max Weber (2000) coloca a ênfase da pesquisa social sobre a vida, sobre a experiência, sobre a heterogeneidade, e, assim, a pluralidade nelas implícita, acarreta diferentes interpretações. Alfred Schutz (1979), na esteira das novas posições teóricas defendidas por Weber e seguindo a tradição fenomenológica, faz uma costura entre experiência e alteridade ao propor a orientação da análise na direção do outro. O que isso quer dizer? Schutz (1978) demonstra que é no contraste entre a experiência que vivo e a que você vive ou que os outros vivem que se funda a compreensão de mundo vivido. A experiência vivida cria a proximidade entre mim e o outro, construindo o grupo, as situações sociais e culturais. Da experiência do mundo vivida em grupo, coletivamente, emerge a experiência do pensamento.

É na relação social cotidiana que os significados são criados e a ela incorporados, conferindo sentido à ação social dos indivíduos envolvidos na relação. Schutz (1979), concebe o mundo social como resultado e consequência de uma interação permanente entre os indivíduos entre si, entre o meio social e o meio ambiente físico, entre o mundo dos contemporâneos e o mundo dos antecessores e, ainda, considerase o mundo dos parceiros da experiência constitutiva do mundo vivido. Berger e Luckmann (1995), fazem uma análise fenomenológica da experiência subjetiva da vida cotidiana, devendo-se aprender a partir dela, logo, a realidade é socialmente construída. Para eles, o senso comum comporta, como Schutz (1979) já havia mostrado, uma pluralidade de interpretações sobre a realidade cotidiana. Berger e Leckumann (1995) enfatizam que a realidade cotidiana se impõe à consciência.

A consciência é sempre intencional; sempre "tende para" ou é dirigida para objetos. Nunca podemos apreender um suposto substrato de consciência enquanto, tal somente a consciência de tal ou qual coisa. Isto é, pouco importando que o objeto da experiência seja experimentado como pertencendo a um mundo físico externo ou apreendido como elemento de uma realidade subjetiva interior (BERGER; LUCKMANN, 1995, p. 37). 
O real é aquilo que se apresenta à minha consciência, na vida cotidiana e se organiza em torno do meu corpo no meu presente, ou seja, abarca os fenômenos que estão presentes aqui e agora, tanto aqueles próximos quanto aqueles distanciados (no espaço e no tempo), isto é, partilho a realidade cotidiana com outros. A experiência compartilhada com o outro ocorre na situação vida face à face. O meu "aqui e agora" confronta com o "aqui e agora" do outro e, na nossa vivência, apreendemos um com o outro, por meio de nossa expressividade.

Na situação face à face, a subjetividade do outro me é acessível e, reciprocamente, a minha também é acessível à ele. Geertz (1987), concebe a cultura como teia de significados, como sistema ordenado de significados e símbolos que permitem a comunicação humana. A linguagem simboliza a cultura. A função simbólica é universal, constituindo uma espécie de segundo código, operando ao lado do código genético. Os símbolos portam concepções. As proposições simbólicas articulam o mundo e oferecem orientações de ações sobre ele.

\section{UM AGENTE FUNDAMENTAL: A FAMÍLIA}

A organização do grupo familiar, como já ressaltamos, varia de cultura para cultura e, às vezes, no interior da mesma cultura. O estudo antropológico de diferentes culturas permitiu identificar várias categorias de família (elementar, extensa, composta). A família do tipo elementar, também chamada nuclear, simples, primária, é uma unidade da organização social, basicamente formada por um homem, uma mulher e seus filhos. Em nossa sociedade, essa categoria de família apresenta uma variante, chamada maternal, formada por uma mulher e seus filhos. A família extensa, também chamada múltipla, é formada de duas ou mais famílias elementares, ligadas por laços consanguíneos.

A família extensa pode ser composta pela linha de parentesco materno ou paterno e por mais de uma geração, com residência comum ou dispersa. A família extensa é um arranjo familiar que ocorre em nossa sociedade, tanto na área rural como na área urbana, incluindo os grandes centros; esse grupo familiar é mais comumente formado pela mãe, filhas e/ou filhos (com seus cônjuges ou não) e seus netos, residindo numa 
mesma casa ou em "puxados", num mesmo terreno. Nem todos os filhos integram essa classificação de família extensa. A criança tem participação ativa no próprio processo de socialização, mas ela depende fundamentalmente dos agentes socializadores e das condições de socialização.

O desejo de vir assemelhar-se a uma outra pessoa, particularmente ao pai ou à mãe, motiva a criança a aceitar e adotar as características e imita as ações da pessoa. É mais propensa a imitar o comportamento de um modelo positivo que o de um outro destituído de atrativos. Os pais são geralmente modelos positivos porque são vistos como figuras revestidas de autoridade, porque são eles que fornecem a ambientação e porque são competentes (MANNING, 1977, p. 107).

Os demais integrantes do grupo doméstico são também agentes socializadores significativos. As ações de socialização, mediante várias práticas, estimulam a atenção, a observação, o interesse pelas coisas e pelas pessoas, a descoberta. Ao mesmo tempo, começa a aprender um código de expressão de sentimentos e emoções. Algumas expressões são reforçadas e outras são controladas, reprimidas. Segundo Bandeira (1988), a criança aprende várias linguagens, embora se comunique, principalmente, com a linguagem corporal.

\section{UMA AÇÃO FUNDAMENTAL - A FALA}

Para inserção da criança na ordem da cultura, a aquisição da fala é um objetivo perseguido constantemente em dois planos complementares: no plano físico, pela domesticação do ouvido, das cordas vocais, do diafragma, dos diversos órgãos envolvidos na fala, e, no plano da significação, pela simbolização. A produção da fala só se tornou viável porque a estrutura do cérebro humano e os órgãos que compõem o aparelho fonador possibilitou a palavra.

O desenvolvimento da linguagem na criança é materializado em modificações quantitativas e quantitativas na compressão e produção verbal. A descrição e explicação dessas modificações é o objeto de estudo do ramo de conhecimento se designa por aquisição da linguagem. Compreender a evolução de um ramo do conhecimento, neste caso a aquisição da linguagem (FREITAS; SANTOS, 2017, p. 4). 
A aprendizagem da linguagem oral é social e ocorre entre duas pessoas ou mais. Ela sofre mudanças e se transforma através do tempo. Aprender a linguagem oral não é apenas saber codificar e decodificar, mas utilizar os signos a partir de conjuntos de sinais (CRUVINEL, 2010). A palavra é mais que sua materialidade sonora, ela é mais que o resultado de uma combinação de sons (feita pelos dos órgãos vocais), combinação a que se atribui valor simbólico (feito pelo pensamento). Ela só constitui a fala, a língua, quando um grupo de indivíduos, uma coletividade, passa a adotar essa combinação de sons com os mesmos valores e a usá-las para expressar as mesmas ideias com os mesmos sentidos. A associação entre os sons e a significação que lhes é atribuída é arbitrária fomenta a aprendizagem e o uso social da língua. Isso faz com que ela se atualize e seja perpetuada.

No que concerne a socialização, nosso foco de interesse, a língua exerce uma importância especial e essencial. Para aquilatar essa importância, basta observar o processo de socialização de crianças surdas e crianças portadoras de audição. Mesmo com todo avanço representado pela linguagem de sinais, por técnicas de leitura labial que ampliaram a abrangência da socialização das crianças surdas, certas áreas da cultura não Ihes são acessíveis. A criança é socialmente pressionada a falar. A expectativa social da fala é de tal ordem que as crianças, cujo ritmo de aquisição é mais lento, tendem a ser submetidas a contínuo estresse no sentido de falar; as que têm ritmo mais rápido são festejadas, valorizadas e também pressionadas a exibir suas habilidades linguísticas. A fala, portanto, além de código de comunicação, é um valor.

Falar cedo e "corretamente" é fonte de admiração para a criança e de prestígio para seus pais no meio social em que vivem. Nas sociedades ocidentais, a ideia de criança se constitui, segundo Ariès (1981), no processo histórico da relação criança-família. Conforme o mesmo autor, as ideias de infância e família na Idade Média não eram investidas dos conteúdos sociais que mais tarde adquiriram. Não se atribuía importância especial à infância, até então caracterizada como fase transitória, sem significado social. 


\section{CONTEXTOS SOCIOCULTURAIS}

A pouca importância e a ausência de cuidados voltados para o bem-estar criança têm seu fulcro, no entender de Áries, na mortalidade infantil, aspecto demográfico característico da época. Na Idade Média, morriam muitas crianças. A alta incidência da mortalidade infantil obliterava a relação com a criança que se tornava pouco importante. As famílias tinham, então, muitos filhos, e, desse modo, assegurava-se que apenas alguns sobrevivessem, deslocando o foco valorativo da criança para a prole. Na modernidade, a separação da criança do mundo adulto se dá no bojo da separação entre igreja e Estado. A ideia de criança como ser indefeso, que requer respeito e cuidado, começa a adquirir contornos mais claros e a ganhar força no século XVII. Os adultos começam a valorizar a relação com criança, a dispensar-lhe atenção, a brincar com elas e animá-las.

Essa mudança de atitude foi acompanhada de mudanças relativas ao cuidado, surgindo preocupações com higiene e saúde, com a aquisição de "bons modos", finalmente com um bom estado emocional da criança. O "sentimento de infância" é visto por Ariès (1978) como uma produção cultural que se desenvolve com à valorização do espaço privado, associada à valorização da individualidade no contexto da vida familiar. Essa cultura se desenvolve numa mudança de representação social da criança e da orientação cultural em relação à sua posição na família, fazendo dela o centro de cuidados, de atenção. A criança ganha importância na família, na vida social. A duração da infância é variável e Ariès (1978) utiliza conceitos de "infância curta". Tem como referente dialético a "infância longa", que perdura ao longo do ciclo básico de escolarização.

Cabe inferir, considerando o contexto aqui apresentado e discutido, que, na nossa sociedade, a ideia de infância "curta" ou, ainda, de infância "Ionga" se correlaciona com a situação de classe. A contribuição de Ariès (1978) foi, sem dúvida, muito importante. Outras análises voltadas à questão da infância foram sendo feitas, tendose, como enfoque, as classes sociais. As diferentes classes têm diferentes estilos de lidar com a infância. Essas diferenças de estilo têm relação com a organização familiar e, ainda, deve-se destacar que os contextos desta socialização variam conforme as 
classes sociais. No Brasil, as crianças escravas já executavam tarefas, pois a socialização se orientava para o bem servir, para a versatilidade de habilidades, para o bem-fazer. Desenvolviam habilidades desde muito cedo, cujo intuito era aprender ofícios, isto é, a criança aprendia a ser uma boa escrava.

O pequeno Gastão, por exemplo, aos quatro anos já desempenhava tarefas domésticas leves na fazenda de José de Araújo Rangel Gastão, nem bem se pusera de é e já tinha um senhor. Manoel, aos oito anos, já pastoreava o gado da fazenda de Guaxindiba, pertencente à baronesa de Macaé (...). O aprendizado da criança escrava se refletia no preço que alcançava. Por volta dos quatro anos, o mercado ainda pagava uma aposta contra altíssima mortalidade infantil. Mas ao iniciar-se no servir, lavar, passar, engomar, remendar roupas, reparar sapatos, o preço crescia trabalhar em madeira, pastorear e mesmo em tarefa próprias do oito, preço crescia (GÓES e FLOENINO, 200, p. 184).

Enfatizamos que o contexto sociocultural escravista e que a criança escrava, por extensão as crianças pobres, eram vistas como "crias", cujo valor se circunscrevia à reprodução da força de trabalho rentável. A família patriarcal se organizava em torno da centralidade do pai. As crianças, assim como a mãe, deviam-lhe obediência, reverência, temor, pois o pai era detentor de poder quase absoluto sobre a mulher, a prole, os escravos, os trabalhadores livres a ele legalmente subordinados. A transição do trabalho escravo para o trabalho livre não foi acompanhada por mudanças significativas do contexto sociocultural de socialização, que prosseguiu cultivando a desigualdade como sua marca característica. A sociedade republicana, caracterizada pela rigidez dos limites de classe, pela enorme distância entre as camadas pobres e a minoria rica, conservava as tradições forjadas na Colônia e no Império, mantendo a visão do mundo social repartido pela desigualdade.

A representação social da pobreza como produção do próprio indivíduo, isto é, como incapacidade pessoal de conquista, com falta de vontade de trabalhar para ser bemsucedido, transfere, para o pobre, a responsabilidade de sua pobreza, resguardando a sociedade e a classe dominante de quaisquer responsabilidades. Essa representação é uma poderosa fonte de significados de caráter desqualificativo, fundamentando a restrição dos direitos sociais da pessoa pobre. O afastamento da sociedade e do Estado em relação à infância pobre, associado à impotência da família 
em garantir proteção às suas crianças e em assumir plenamente seu lugar central como agente de socialização, abriu espaço à emergência de formas alternativas de socialização, entre as quais a da rua. Muitos são os desvios da socialização, mas, para os propósitos de iniciação nessa problemática, trataremos de três: trabalho infantil, abandono e vitimarão de violências.

Tânia Dauster (1992), com base nos dados da pesquisa, analisa a configuração simbólica do trabalho infantil como opção própria, articulando-a com valores morais familiares. Além de ganhar o próprio dinheiro para participar do orçamento familiar e para comprar algum bem de uso pessoal, com o trabalho, a criança busca, também, e, principalmente, conquistar, segundo Dauster, a autonomia de se inscrever na "gramática do gosto", ou, dito de outro modo, de andar na onda, na moda, usando o tênis, a roupa, os acessórios que a cultura do consumo transforma em objetos em desejos. Pelo enfoque que estamos dando ao que chamamos desvios da socialização, o abandono constitui um imenso fosso de privação da infância. Uma sociedade com uma desigualdade social tão profunda como a nossa, com uma distância tão imensa entre ricos e pobres, nas camadas populares os adultos se mobilizam integralmente em torno do esforço de obtenção dos meios de vida, deixando suas crianças entregues ao desamparo.

\section{DESVIOS DA SOCIALIZAÇÃO E AÇÕES VITIMADORAS DA CRIANÇA}

Uma das consequências sociais da pobreza é a vitimação das crianças pelo abandono, principalmente no meio urbano. Pais e mães saem muito cedo para o trabalho e deixam seus filhos sob a guarda uns dos outros ou de outras crianças. Essa não é a única prática. Outras saídas são buscadas por estratégias como a solidariedade espontânea da vizinhança ou a cooperação induzida. Quando uma mulher, por qualquer motivo (incluindo desemprego), permanece em casa, as mães que trabalham buscam nela o apoio necessário, pedindo sua colaboração para "tomar conta" das crianças. 
No mundo ocidental, a violência e o abandono de crianças por adultos é fato milenar. Na tradição judaica, a criança sofria abandono tanto pelos pais como pelo Estado. $\mathrm{O}$ ato dos pais de desampararem seus filhos era perfeitamente aceito, já que estes tinham poder de vendê-los, caso necessitassem ou simplesmente não quisessem dividir os bens. Muitas crianças eram raptadas, arrancadas de seus pais, a fim de servirem de mão-de-obra barata ou escrava; outras eram vítimas de diversos tipos de agressões, das mais variadas possíveis, desde abusos sexuais até maus tratos físicos, como quebrar membros ou furar olhos, para obter compaixão dos transeuntes (ARAÚJO et al, 2004, p. 149).

O abandono familiar, entretanto, é corolário de um abandono maior e mais amplo: o abandono do Estado e da sociedade. Estado e sociedade não têm a criança como preocupação central, como prioridade. Políticas públicas de proteção à infância são ainda inconsistentes e tímidas. A sociedade política não tem, para a infância, projetos consistentes fora do domínio da retórica. Crianças não formam opinião, não votam, não são força política de peso no jogo do poder. Elas só seriam se a sociedade em que nascem as acolhessem bem, que fossem valor. No entanto, estamos longe de garantir às nossas crianças a necessária assistência: social. O Estatuto da criança e do adolescente, Lei № 8,069, de 13.07.1990, é marco importante no campo dos direitos da criança, mas há muito para caminhar, pois as leis/por si só não transformam a sociedade e a cultura, embora criem bases para mudanças.

\section{MEIOS DE COMUNICAÇÃO, NOVOS AGENTES DE SOCIALIZAÇÃO}

As tecnologias da comunicação nos tempos atuais, como outrora foi a fala no alvorecer da humanidade e a escrita no raiar das civilizações, invadiram a vida social, infiltrando-se nos espaços. É a partir delas e com elas que a comunicação e a informação alcançaram alto nível de capilaridade, inundando o espaço e a vida privada, instalando-se no cotidiano doméstico como uma presença constante e indeclinável. As telecomunicações e a informática se enredam cada vez mais nesse cotidiano doméstico, elaborando novas maneiras de convívio familiar, trazendo para nossas casas novos atores, novos agentes de socialização. 
É fácil constatar que, enquanto os shoppings estão repletos de adolescentes, os grêmios e diretórios acadêmicos estão quase vazios. O que mais se podia esperar de uma geração que teve como agente de socialização a televisão, tem como amigo do peito o computador, como meta o vestibular e como opção de lazer os espaços fechados e seguros dos centros comerciais? (NASCIMENTO, 2005, p. 24).

A televisão e o computador trazem às nossas casas atores com os quais não temos intimidade, mas que têm poder de interferir em nossas rotinas e em nossas relações, transformar nossa forma e nosso modo de viver, desestabilizar nosso universo familiar, afetar profundamente as pautas de nossa educação familiar. As cenas das mídias invadem a cena doméstica e os nossos processos de representação. Por consequência, infiltram-se em nossos processos de construção de pessoa, de construção de identidade, colocando-nos cada vez mais expostos aos contingenciamentos de subjetividades mutantes. A crítica às dimensões de opressão que as tecnologias da informação comportam, conquanto necessárias e pertinentes, refratadas no percurso de sua vulgarização, tendem a criar uma concepção maniqueísta de que seriam uma encarnação contemporânea do mal.

As tecnologias da informação que criaram as condições da sociedade em rede passaram a encarnar o mal e as formas de interatividade que trariam a semente desse mal. Não é bem assim. Elas vêm se tornando invasivas, mas não se impõem ao social de modo tão absoluto, que não restem espaços de negociação. O grupo familiar está diante de novos atores com os quais partilha as ações de socialização e com os quais estão constituindo nova expressão de cultura doméstica. Assim como partilhamos a vida doméstica com parentes, empregados domésticos, amigos, vizinhos, revistas, cinema, rádio e soubemos culturalmente resguardar, como pais, a precedência de nossas orientações, também seremos capazes de relativizar as ações de socialização de atores televisivos e virtuais que ingressam em nossa casa. Mais uma vez, o cuidar é o caminho e o abandono, o descaminho.

A televisão se impõe cada vez mais ao ambiente doméstico, abrindo novas formas de experiência e se envolvendo no jogo de construção da realidade. Ela é parte do mundo e da vida da criança, participando continuamente da produção de sentidos, atando novos nós à teia de significados em que estamos envolvidos. É relevante destacar 
que há pouquíssimas opções de programas dedicados ao público infantil. Entre eles, muitos são enlatados, produzidos em outros países, com pautas culturais diferentes da nossa cultura. Por falta de opções e pelo controle da televisão submetido ao domínio do interesse dos adultos, ao início da noite e no chamado horário nobre no período noturno, as crianças acabam espectadoras de programas voltados para o público adulto.

Esse horário, até mesmo pela tendência de maior audiência do público economicamente ativo, constituído pela massa de consumidores a quem os patrocinadores querem atingir com sua publicidade, e a propaganda de seus produtos, é geralmente reservado a noticiários e a folhetins. Os telejornais cada vez mais apresentam a notícia como espetáculo e adotam um formato que reserva certo destaque a catástrofes, desastres e, principalmente, à violência. As telenovelas trazem às telinhas, sob outra roupagem, a mesma receita básica dos super-heróis, explorando, nesse processo, um "pseudodebate" entre o bem e o mal, como uma constante universalista e não como uma visão de mundo, uma concepção da vida humana daqueles que os produzem.

O grande problema que a sociedade brasileira enfrenta em relação aos agentes virtuais de socialização é que as famílias, em larga medida pouco escolarizadas, não estão preparadas para a interação (harmoniosa ou conflitiva) com eles no processo de socialização, a partir de um repertório ampliado de formas simbólicas, com um leque diversificado de valores. A "internet", tanto quanto a televisão, têm conquistado espaço no universo familiar, estabelecendo novos fluxos de comunicação, novos focos de relação. As crianças, nos seus primeiros anos de vida, interagem com os computadores. Embora a televisão já tenha se disseminado de forma bem mais radical nos lares brasileiros, os computadores estão chegando e com ele as tecnologias de bandas largas tendem a fazê-lo com força e velocidade maiores.

Os celulares, nesse cenário, despontam como suporte eficaz e efetivo de convergência das mídias. A rede, como outros espaços quaisquer, oferece boas oportunidades, muitas alternativas atraentes, mas também oferece riscos, esconde perigos. Não é possível apagar a conexão da família com a rede e essa nem seria a 
orientação desejável. Mecanismos de controle começam a ser desenvolvidos, mas, de modo geral, há reboque dos desvios eletrônicos da socialização. As novas tecnologias de comunicação não distinguem espaços privados e públicos, elas se expandem sem considerar qualquer outro limite que a restrição ao acesso pela renda.

Mais uma vez o conhecimento e a informação é que podem instrumentalizar os pais na interação com os outros agentes de socialização para que ensinem os seus filhos, desde muito cedo, a desenvolver uma postura de diálogo e de negociação, respeitando, nesse processo, as suas escolhas.

\section{USOS E ABUSOS DOS MEIOS DE COMUNICAÇÃO}

As ações socializadoras dos meios de comunicação estão profundamente vinculadas à cultura do consumo. É na cultura do consumo que encontramos os novos estímulos aos usos e abusos da criança, convertendo-a em mediação de violência contra si mesma. A imagem da criança é idealmente associada à inocência, à pureza e à sentimentos de ternura, carinho. Por isso mesmo, tende a comover, a estimular afeto. Esse campo semântico que a imagem da criança circunscreve impregna idealmente não só a criança, mas a relação idealizada com ela. São muitas as formas de uso e de abuso da criança em razão da cultura do consumo, que acarreta consequências na construção da criança enquanto pessoa, nas suas práticas e escolhas. Trata-se do uso exagerado da imagem da criança na publicidade; do abuso da criança em sites pornográficos; do uso excessivo da criança como pressão de consumo.

As crianças pequenas são atraídas por informações visíveis e concretas, pouco familiares, dramáticas e até mesmo amedrontadoras. Isso ajuda a explicar por que elas são tão facilmente seduzidas por ações violentas e pela aparência física sexy (seios grandes, pouca roupa), bem como pelo comportamento sexy (flertar, posar, abraçar muito). Também ajuda a explicar por que os marqueteiros usam imagens dramáticas, incluindo as sensuais e violentas, para capturar a atenção das crianças e venderIhes coisas (LEVIN; KILBOURNE, 2009, p. 63).

Parece-nos conveniente fazer uma distinção preliminar entre publicidade e propaganda para construir uma via de entendimento comum aos efeitos de sentido que um ou outro termo agregam ao contexto em que estão sendo usados. Filmes de 
propaganda exibem casais de crianças "apaixonados". Folhetins já começam a incorporar, em suas tramas, narrativas de experiências sentimentais carregadas de erotismo entre crianças. O corpo erótico, no discurso do desejo, dá expressão ao eu desejado e ao eu desejar-te. Reduzir o erotismo ao apelo do prazer sexual é retirarIhe parte importante de sua significação primordial

\section{RESULTADOS E DISCUSSÕES}

A criança começa a ser socializada na cultura da família desde seu nascimento e deve aprender a lidar com as sensações de frio, calor, fome, sede, alegria e tristeza, com a finalidade de conhecer seu corpo para poder se relacionar e conviver com outras pessoas, devendo, também, aprender a língua materna e, também, o valor do símbolo verbal, estabelecendo padrões básicos de comportamento, enfim, dominando os códigos sociais. Para inserção da criança na ordem da cultura de aquisição da fala não basta somente a maturação biológica, ela deve domesticar o ouvido, aprender usar as cordas vocais. A intervenção direta do adulto é necessária e determinante ao desenvolvimento da linguagem oral. Este aprendizado não conduz, apenas, a criança a saber codificar e decodificar, mas utilizar os signos por meio de conjuntos de sinais (CRUVINEL, 2010). A criança aprenderá que existem coisas ao seu redor, objetos brinquedos.

À medida que cresce, aprende o que pode ou não fazer e as normas e costumes daquela sociedade a que pertence. Schutz (1979) aponta que é por meio do processo de aprendizagem, de socialização, que os indivíduos se tornam herdeiros de uma tradição cultural e a transmitem, concebem o mundo social, o meio ambiente físico e a interação entre o mundo dos contemporâneos, o mundo dos antecessores e o mundo dos parceiros da experiência constitutiva do mundo vivido. O problema aqui é a comunicação mercadológica voltada ao público infantil, utilizada de forma abusiva, pois considera-se as crianças como consumidores, isto é, estas empresas não possuem o compromisso social e estas ações refletem diretamente nas crianças, acelerando o seu desenvolvimento prematuro. A criança tem participação ativa no próprio processo de socialização, mas ela depende fundamentalmente dos agentes socializadores e das condições de socialização. 
O sentimento de infância visto por Ariès (1978), voltado à produção cultural, desenvolve-se na valorização do espaço privado, valorizando a individualidade no contexto familiar, e, assim, altera a representação social da criança e a orientação cultura em relação a sua posição na família, variando conforme as classes sociais. Uma das consequências sociais da pobreza é a vitimização das crianças pelo abandono, principalmente no meio urbano. Pais e mães saem muito cedo para o trabalho e deixam seus filhos sob a guarda uns dos outros ou de outras crianças. $O$ afastamento da sociedade e do Estado em relação à infância pobre, associado à impotência da família em garantir proteção às suas crianças e em assumir plenamente seu lugar central como agente de socialização, abre espaço à emergência de formas alternativas de socialização, entre as quais a da rua.

Muitos são os desvios da socialização, mas, para os propósitos de iniciação nessa problemática, tratamos de três: trabalho infantil, abandono e vitimização de violências. Pelo enfoque que estamos dando ao que chamamos desvios da socialização, o abandono constitui um imenso fosso de privação da infância, e, portanto, a sua menção no escopo deste estudo é imprescindível. Uma sociedade com uma desigualdade social tão profunda como a nossa, com uma distância tão imensa entre ricos e pobres, nas camadas populares os adultos se mobilizam integralmente para o de obtenção dos meios de vida, deixando suas crianças entregues ao desamparo. É importante ressaltar que não é mais o encurtamento da infância que se está operando, mas a dissolução da fronteira entre ser criança e ser adulto diferenciando-os como consumidor.

Mais uma vez, o cuidar e orientar é o caminho, contudo, os meios de comunicação se impõem cada vez mais ao ambiente doméstico, havendo poucos programas dedicados a faixa etária, e, assim, deixam de fomentar novas formas de interação adequadas à este público. $\mathrm{O}$ grande problema que a sociedade brasileira enfrenta em relação aos agentes virtuais de socialização é que as famílias, em larga medida, são pouco escolarizadas, não estão preparadas para a interação (harmoniosa ou conflitiva) com eles no processo de socialização a partir de um repertório ampliado de formas simbólicas e de um leque diversificado de valores. Essa ação socializadora da 
publicidade e propaganda é lesiva à criança, pois a envolve numa assunção do poder exercido com prepotência, como dominação na dimensão do consumo e tendendo ao deslizamento para outras dimensões da vida comum.

Mais e mais crianças "adultas" estão se replicando. A resolução 163 do Conselho Nacional do Direito das Crianças e Adolescentes (Conanda) publicada no dia 4 de abril de 2014, relata o que é a abusividade, concepção prevista no Art. 37, $\S 2^{\circ}$, do Código de Defesa do Consumidor, que proíbe a publicidade para as crianças com a finalidade de compra, produto ou serviço. Mais uma vez, o conhecimento e a informação que podem instrumentalizar os pais na interação com os outros agentes de socialização, para ensinar seus filhos, desde muito cedo, a desenvolver uma postura de diálogo e de negociação. São elementos essenciais ao uso consciente do recurso midiático, pois o interesse pelas descobertas, ao mesmo tempo, favorece o aprendizado de certas sentimentos e emoções, reforçando algumas expressões, enquanto outras são reprimidas.

\section{CONSIDERAÇÕES FINAIS}

A família é o espaço para a promoção do desenvolvimento social, porém, o indivíduo, a partir das instituições sociais, dos processos de socialização e dos determinantes históricos, sociais e simbólicos, sofre transformações. A infância é um produto mercadológico, e, assim, sofre toda a forma de exploração possível. Os responsáveis pela criança devem estar atentos e preparados para inserção de novas mídias no diaa-dia da criança, mas, para que isso aconteça, é indiscutível a necessidade de acompanhar a evolução tecnológica, pois as crianças já nascem imersas na tecnologia e possuem um fácil entendimento sobre elas. O diálogo, o acompanhamento e, principalmente, o bom relacionamento com os filhos, ajudam no aprendizado dos conceitos do uso digital.

A partir das discussões aqui elencadas e discutidas, é possível concluir que as mídias devem ser utilizadas com limites, e, desse modo, não devem ser usadas como pacificadoras emocionais, e, assim, é crucial que os canais de "TV" da "internet", jogos, dentre outras ferramentas, sejam configurados pelos responsáveis pela 
criança, isto é, devem ser adequados à sua faixa etária, e, desse modo, certos cuidados são essenciais, pois os marqueteiros, a mídia e o consumismo procuram explorar este público e as consequências são desastrosas para a criança, que avança inadequadamente as etapas de seu desenvolvimento cognitivo, sendo a principal consequência a perda da sua infância, acarretando-se problemas como a frustração, problemas de saúde e de ansiedade neste público.

\section{REFERÊNCIAS}

ARIES, P. História Social da Criança e da Família. $2^{\underline{a}}$ ed. Rio de Janeiro: Ed. Guanabara, 1981.

BANDEIRA, M. de L. Antropologia: cultura e sociedade no Brasil. Cuiabá: EdUFMT, 1995.

BANDEIRA, M. de L. Antropologia: diversidade cultural e educação. Cuiabá: EdUFMT, 1995.

Território negro em espaço branco. São Paulo: Editora Brasiliense, 1988.

BERGER, P.; LUCKMANN, T. A construção social da realidade. Petrópolis (RJ): Ed. Vozes, 1995.

CORSARO, W. A. Sociologia da Infância-2. Porto Alegre: Penso Editora, 2011

CRUVINEL, F. R. Ensinar a ler na escola: a leitura como prática cultural. Ensino EmRevista, v.17, n.1, p. 249-276, jan./jun.2010.

DAUSTER, T. Uma infância de curta duração: trabalho e escola. Cadernos de Pesquisa, n. 82, p. 31-36, 1992.

ARAÚJO, M. de. F.; MATTIOLI, O. C. Gênero e violência. Fortaleza: Arte \& Ciência, 2004. 
DIMENSTEIN, G. A guerra dos meninos: assassinatos de meninos no Brasil. São Paulo: Editora Brasiliense, 1990.

DURKHEIM, E. Educação e sociologia. [1922]. São Paulo: Melhoramentos, 1967.

ELKIN, F. A criança e a sociedade: o processo de socialização. Trad. A. Blaustein. Rio de Janeiro: Bloch, 1968.

FREITAS, M. C. de. (Org). História Social da Infância no Brasil. 5ª ed. São Paulo: Cortez, 2003.

FREITAS, M. J.; SANTOS, A. L (Eds.). Aquisição de língua materna e não materna: Questões gerais e dados do português (Textbooks in Language Sciences ). Berlin: Language Science Press, 2017.

GEERTZ, C. Nova luz sobre a Antropologia. Rio de Janeiro: Paz e Terra, 1987 Saber Local: Novos ensaios e Antropologia Interpretativa. Trad. Vera Mello Jorcelyne. Petrópolis (RJ): Ed. Vozes, 1997 Interpretação das culturas. São Paulo: Zahar, 1987

Giddens, A.; Figueiredo, A.; SOBRAL, J. M. Sociologia. 6ª ed. Lisboa: Fundação Calouste Gulbenkian, 2008.

GOES, J. R. de.; FLORENTINO, M. "Criancas escravas, crianças dos escravos". In: PRIORE, M. de.[Orq.]. História das crianças no Brasil. São Paulo: Contexto, 2004, p. 177-191.

LEVIN, D. E.; KILBOURNE, J. A infância perdida: como orientar nossas crianças na era da sexualidade precoce. São Paulo: Editora Gente, 2009.

LIMA, L. de. O. Piaget para principiantes. São Paulo: Grupo Editorial Summus, 1980. MANNING, S. A. Desenvolvimento da criança e do adolescente. São Paulo: Editora Cultrix, 1977. 
MATTA, R. da. O que faz o Brasil, Brasil? Rio de Janeiro: Rocco, 1991.

NASCIMENTO, A. B. Quem tem medo da geração shopping? Uma abordagem psicosocial. 2ª ed. Salvador: SciELO-EDUFBA, 2005.

NICOLACI-DA-COSTA, A. M. Sujeito e Cotidiano: um estudo da dimensão psicológica do social. Rio de Janeiro: Compus, 1987.

NUNES. B. F. Sociedade e infância no Brasil. Brasília, (DF): Editora Universidade de Brasília, 2003.

ROUSSEAU, J.J. Emílio ou da educação. $39^{a}$ ed. Trad. de Sérgio Millet. Rio de Janeiro: Bertrand Brasil, 1995.

SCHAEFER, R. T. Sociologia. Porto Alegre: AMGH Editora, 2006.

SCHERR, A. Sozialisation, person, individuum. In: SCHÄFERS, B. (Hrsg.). Einführung in Hauptbegriffe der Soziologie. 6. erw. Aufl. Opladen: Leske und Budrich, 2002.

SCHUTZ, A. Fenomenologia e relações sociais. Rio de Janeiro: Zahar, 1979.

TEDRUS, D. M. A. S. A relação adulto-criança. Campinas: CMU/Unicamp, 1998.

VEITH, H. Sozialisation als reflexive Vergesellschaftung. Zeitschrift für Sozialisationsforschung und Erziehungssoziologie, Weinheim, n. 2, 2002.

Enviado: Abril, 2020.

Aprovado: Agosto, 2020. 